Organizational Culture in Local and Multinational Organizations in Egypt Dr. Mohammad M. Al-Kalyoubi

\title{
Organizational Culture in Local and Multinational Organizations in Egypt
}

\author{
Dr. Mohammad M. Al-Kalyoubi
}

Mohamed_elkaloubi@cic-cairo.com

Assistant Professor of Management- School of Business- CIC

\section{Abstract:}

A solid, robust and clearly-observed organizational culture is indispensable for organizations to achieve strong economic and financial performance in a competitive environment, as the extensive literature on organizational culture shows. As such, gaining insights as to specifics of organizational culture is of importance for practitioners and academics alike. This study contributes to the organizational literature by investigating the different types of corporate cultures observed in both local and multinational firms coexisting within the same national setting in Egypt, identifying which culture types are more dominant. The findings show that the dominant type of corporate culture in both local and multinational companies is the same (clan culture). Meanwhile, although similarities in culture type were discovered, the indicative strength of the culture types differs, and this may indicate one explanation for the perceived stronger performance in multinationals. However, it would seem that the most

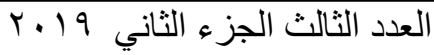

المجلد العاشر 
Organizational Culture in Local and Multinational Organizations in Egypt Dr. Mohammad M. Al-Kalyoubi

important explanatory factors may lie elsewhere. Moreover, this result clearly shows the effect of national culture on corporate culture, in terms of the impact of being located in Egypt with largely Egyptian staff in both cases.

Keywords:

- Organizational Culture

- MNCs (Multinational companies)

- OCAI (Organizational Culture Assessment Instrument )

\section{Introduction}

It can be observed that some local Egyptian firms attribute the outcome of their activities to external factors (e.g., market conditions, inflation, and the macroeconomic condition at large) instead of factors existent within the organization such as organizational culture and behavioral variables. Meanwhile, it can be contended that there is a remarkable difference between local Egyptian companies' performance and financial results compared with multinational organizations operating in Egypt, despite the fact that they hire in most cases employees from the same pool and with the same qualifications. Thus, there is an ambiguity towards the real reasons stand behind both the good and poor organizational performance of these companies.

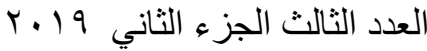

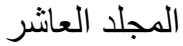


Organizational Culture in Local and Multinational Organizations in Egypt Dr. Mohammad M. Al-Kalyoubi

Therefore, there is a need to investigate the dominant corporate cultures types found in both local and multinational companies operating in the Egyptian market - this has not been studied before. Accordingly, this study aims at diagnosing, and describing the most dominant culture type existing in both local and multinational companies in the Egyptian market, testing the significance difference and similarity between the dominant types of culture found in both local and multinational companies in the Egyptian market.

A form of organisational capital (Kaliprasad 2006), organisational culture has been defined as an organisation's beliefs, attitudes, and behaviours that collectively define its values (Miller, 2004). Organisational culture, therefore, is one of the key components influencing an organisation's ability to compete and succeed in both short and long terms (Kotter and Hesket, 1992). In this respect, organisational culture is a widely accepted, however not universally interpreted phenomenon in an organisational setting (Cameron and Quinn, 1999).

It is agreed that Hofstede's (1980) studies conducted on national culture are responsible for stimulating academic interest in specifying organisational culture via providing a theoretical foundation for scholars to adhere to and generate testable statements in accordance with. Indeed, organisational culture is gaining an elevated importance at both the academic and practical levels. Specifically, organisational culture impacts the 
Organizational Culture in Local and Multinational Organizations in Egypt Dr. Mohammad M. Al-Kalyoubi

behavioural aspects observed within organisations, and also affect organisations' interactions with their respective external competition, customers and markets (Rollins and Roberts, 1998).

Furthermore, according to Burt et al. (1994), the role of organisational culture is to coordinate employee efforts through an informal control mechanism that clarifies a firm's goals and practices. In the presence of an organisational culture, employees will have no uncertainty about what they should act and do with regard to different situations and problems they might face and, thus, will be able to respond to different events and circumstances more effectively. That is, organisational culture imparts a code that employees refer to when it comes to aligning their efforts with the objectives of their organisations (Gerard George et al., 1999).

In view of the above, culture is a unity of certain unnoticed and unrecognised set of behaviours conducted by a certain group members (Daft, 2001). Under certain circumstances, beliefs and attitudes, to a great extent, control and unify employees' decisions and actions towards achieving a common goal (Roger Harrison and Stokes, 1992). As a result, it can be argued that acting as a team with harmony in a systematic well defined manner towards achieving a goal or dealing with a serious matter (Feldman, 1991), is the outcome of Organisational Culture.

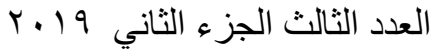

المجلد العاشر 
Organizational Culture in Local and Multinational Organizations in Egypt Dr. Mohammad M. Al-Kalyoubi

Investigating cultural aspects originated from social anthropology (Kotter and Heskett, 1992). Anthropology is interested mainly in studying and comparing habits of different tribes. Hence, unlike management or organisation theory, it is a science that focuses on the behaviour of different tribes' members which is to a great extent very much aligned with both the national and organisational cultures' purposes of studies.

Many studies address the subject of organisational culture mainly highlighting its importance (e.g., Kotter and Heskett, 1992, Greenberg and Baron, 2000, Cameron and Quinn, 2006), defining its types and developing cultural diagnostic tools (e.g., Harrison, 1972, Deal and Kennedy, 1980, Quinn and Rohrbaugh, 1983, Hofstede 1992), and, most importantly, studying its relationship with many other variables especially organisational performance and effectiveness (e.g., Kotter and Heskett, 1992, Denison, 1997,Rollins and Roberts, 1998). However, much work is still needed to (1) uncover other aspects of organisational culture, (2) clarify debates with regard to different researches' findings, and (3) come up with more elaborate theoretical frameworks and models that show the relationship between organisational culture and other related variables with regard to organisational performance and effectiveness.

According to (Kotter and Heskett, 1992), the development of organisational culture as a science is linked with 
Organizational Culture in Local and Multinational Organizations in Egypt Dr. Mohammad M. Al-Kalyoubi

publications in early 1980s (e.g., Ouchi, 1980; Pascal and Athos, 1982; Deal and Kennedy, 1980; Peters and Waterman, 1982). Those studies identify reasons for organisations' success and failure that are beyond what is traditionally documented in earlier literature. Their findings are consistent with the notion that, values and beliefs represent the culture embedded in organisations. Such values and beliefs may be either an advantage or a disadvantage to the organisation. Evidently, an organisation's culture may assist employees within an organisation to work together in order to accomplish their assigned tasks and objectives successfully and smoothly, yet, some organisational cultures may place obstacles in the way of the actions or thinking processes of employees. Thus, a challenge for any organisational researchers is to identify the types of current cultures that exist within organisations. Once this is accomplished, a process can be spelled out to define the specific traditions, programs, or common values the organisation would like to exhibit from within in order to reach and develop a preferable, desired and more effective culture that matches and enhances an organisation's strategic objectives.

Furthermore, many studies emphasize the importance of organisational culture as a less tangible, but more powerful than other market factors (e.g., Kotter and Heskett, 1992, Richard Hagberg, 2003, Cameron and Quinn, 2006,). They regard 
Organizational Culture in Local and Multinational Organizations in Egypt Dr. Mohammad M. Al-Kalyoubi

organisational culture as a major distinguishing factor explaining the success of all companies.

According to Cameron \& Quinn (2006), each culture enjoys a unique language, symbols, rules, regulations and feelings that are different from that of other cultures. Such culture might also be different inside same organizations through different sub occupational, religious, educational or social groups that their differences represent sub cultures; yet, each of those subcultures contains common attributes of the dominant type of culture of the entire organization. Similarly, Thompson and Strickland (1987), confirm that every organization has a unique culture represented in its unique history and style of management, its own ways of addressing and solving its problems and conducting activities, its own established patterns of "how we do things around here ", its own legendary set of war stories and heroes, its own experiences and its unique organization personality. Meaning that every organization has its unique finger print that tries to apply on its existing employees and set it as the base of recruiting and hiring criteria. Schermerhorn, et al. (2004), as well argue about the uniqueness idea of organizational culture and state that just as no two individual personalities are the same, no two organizational cultures are identical. Yet, Denison (2000) believes that If all managers and scholars believe in the uniqueness of organizational cultures, this means that outcomes of researches 
Organizational Culture in Local and Multinational Organizations in Egypt Dr. Mohammad M. Al-Kalyoubi

that indicate the type of dominant organizational cultures found in most successful companies, cannot be either studied or used by other organizations. On the other hand the idea of culture change and all studies related and successful attempts will be impossible. According to Dennison, even if there are many aspects of organizational cultures that cannot be compared, when the objective is to use culture as a lever for change, it is important to begin by focusing on aspects of culture that can be compared.

In this sense, according to Harrison \& Stokes (1992), culture shapes both beliefs and attitudes of all organizations' members and accordingly their behavior and most importantly their performance. It influences the whole organizational life, in terms of the way decisions are taken, the recruitment, promotion and awarding systems and the external systems in general. How people are treated internally, how customers are treated externally, and how organization responds to its environment. In general it influences each and every internal aspect as well as external responses.

Hypothesis 1: Within the Egyptian national setting, the dominant type of organizational culture in multinational firms is not significantly different from the dominant one in local companies.

Hypothesis 2: Within the Egyptian national setting, the indicated strength of the dominant type of organizational culture

العدد الثالث الجزء الثاني 9 ـ ب

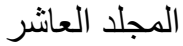


Organizational Culture in Local and Multinational Organizations in Egypt Dr. Mohammad M. Al-Kalyoubi

in multinational firms is not significantly different from the strength of the dominant culture in local companies.

\section{Method}

\section{Participants:}

Population of this study includes both local and multinational companies' employees and managers located in Cairo. The researcher has approached 70 different local and multinational companies in Cairo, where 14 among them (10 local companies and 4 multinational companies) agreed on participating in this research. Moreover, the researcher has adopted Cochran (1963) sampling size equation for large populations, which is the case of this study.

\section{Assessments and Measures:}

Cochran (1963) developed an equation to yield a representative sample for proportions as follows:

$$
\mathrm{N}_{0}=\frac{\mathrm{Z}^{2} \mathrm{pq}}{\mathrm{e}^{2}}
$$

Which is valid where n0 is the sample size, $\mathrm{Z} 2$ is the abscissa of the normal curve that cuts off an area at the tails (1 equals the desired confidence level, e.g., 95\%), e is the desired level of precision, $\mathrm{p}$ is the estimated proportion of an attribute that is present in the population, and $q$ is $1-p$. The value for $Z$ is

العدد الثالث الجزء الثاني 9 ــ

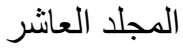


Organizational Culture in Local and Multinational Organizations in Egypt Dr. Mohammad M. Al-Kalyoubi

found in statistical tables which contain the area under the normal curve.

In view of the above, and due to the estimated large number of study population (all employees in both local and multinational companies located in Cairo) the researcher has adopted the practice with regard to large population, therefore he has assumed $\mathrm{p}=.5$ (maximum variability), a 95\% confidence level and $\pm 5 \%$ precision. When calculating the study sample size based on Cochran's (1963) sampling size equation for large populations, the sample size of this study has been determined by the hereunder equation:

$$
\mathrm{N}=\frac{1.96^{2} \times 0.5 \times 0.5}{0.05^{2}}=384 \text { respondents }
$$

Thus the sample size of this study has been determined based on the above equation to be 384 respondent gathered from 14 companies (10 local and 4 multinational) where a random stratified sample applied that included (clerks-supervisors-middle management-senior management). The share of local respondents has been estimated to be $75 \%$ versus $25 \%$ of the multinational respondents. This is based on the researcher's practical and professional experience. Same has been applied while determining the share of every stratum that the researcher assumes to be $60 \%$ employees and senior employees, $20 \%$ supervisors, $15 \%$ middle managers and $5 \%$ senior managers.

العدد الثالث الجزء الثاني 9 ـ ب

المجلد العانشر 
Organizational Culture in Local and Multinational Organizations in Egypt Dr. Mohammad M. Al-Kalyoubi

As previously mentioned, the researcher has approached 70 different companies, among them 10 local and 4 multinational that accepted to participate in this research, thus 300 questionnaires have been given to 10 local companies (30 each) and 100 questionnaire have been given to 4 local companies (30 each) where their Human Resources Managers have been asked to invite employees and managers to fill it in based on the estimated share of every stratum as mentioned above. Meanwhile the researcher has considered distributing 400 questionnaires and not 384 (the sample size required) for errors eliminations of some questionnaires. Meanwhile, 310 respondents have agreed to fill in the questionnaire, however, seventeen respondents have been eliminated due to in-complete questions, thus the final research sample has become 293 respondents.

\section{Procedure:}

The competing value frames developed by Quinn and Rohrbaugh has been used to collect such data as one of the most known and wide used by many researchers, since its Reliability has been indicated by many studies (Quinn and Spreitzer, 1991;Yeung, Brockbank, and Ulrich, 1991; Zammuto and Krakower 1991; Peterson, Cameron, Spencer and White, 1991). Numerous studies have also shown its validity (Cameron and Freeman, 1991; Quinn and Spreitzer, 1991). The OCAI consists of six items. Each item has four alternatives. Respondents should divide 100 points among these four alternatives, depending on 
Organizational Culture in Local and Multinational Organizations in Egypt Dr. Mohammad M. Al-Kalyoubi

the extent to which each alternative is similar to his/her organisation. Scoring the OCAI just needs to add all A responses within the six items and divide them by 6 . Same will be conducted regarding B-C-D responses. C1 stands for clan culture, C2 for adhocracy culture, and C3 for market culture and C4 for hierarchy culture. Authors of OCAI permit purchasers of their book to use their scale for noncommercial academic and research purposes only.

As for the statistical analyses, the Frequency analysis has been used to evaluate the descriptive data concerning employees' responses to the competing value frames as a tool to describe the most dominant type of culture found in both local and multinational companies. Mann-Whitney statistical analysis tool to compare between the dominant types of culture found in both local and multinational companies.

\section{Results}

Frequency analysis has been used to evaluate the descriptive data concerning employees' responses to the competing value frames as a tool to describe the most dominant culture type found in both local and multinational companies. The OCAI consists of six items. Each item has four alternatives. The results indicate that both local and multinational companies' study sample have ranked the Clan culture as the most dominant type of culture found in their companies. The results show that

العدد الثالث الجزء الثاني 9 ــ

المجلد العانشر 
Organizational Culture in Local and Multinational Organizations in Egypt

Dr. Mohammad M. Al-Kalyoubi

113 respondents have ranked the Clan culture as the most dominant type of culture found in local companies with $38.6 \%$ out of the total study sample; that is 293 respondents, while 35 respondents have ranked the Clan culture as the most dominant type of culture found in multinational companies with $11.9 \%$ out of the total study sample. On other words, 148 respondents (local and multinational) with $50.5 \%$ have ranked the clan culture as the most dominant type of culture found in their companies. (See table 1 that shows respondents' ranking with regard to the most dominant type of culture they perceive in their companies local or multinational).

Meanwhile, to test the null hypothesis that states "Within the Egyptian national setting, the dominant type of organizational culture in multinational firms is not significantly different from the dominant one in local companies", the researcher has used Mann-Whitney statistical analysis tool to compare between the dominant type of culture found in both local and multinational companies. The results show that $\mathrm{p}=0.300$. Thus, since the agreed critical p- value of this study is .05(significance level), this means that there is no significant difference between both local and multinational companies with regard to the most type of dominant culture, and that the result fails to reject the null hypothesis. (See table 2 - Mann-Whitney- Local and multinational companies' type of dominant corporate culture).

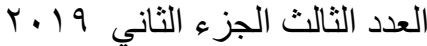

المجلد العاشر 
Organizational Culture in Local and Multinational Organizations in Egypt Dr. Mohammad M. Al-Kalyoubi

Meanwhile, to test the null hypothesis that states "Within the Egyptian national setting, the strength of dominant type of organisational culture in multinational firms is not significantly different from the dominant one in local companies" ( hypothesis 2), the researcher has used Mann-Whitney statistical analysis tool to compare between the dominant type of culture found in both local and multinational companies. The results show the relevant Mann-Whitney $U$ calculated value, its associated Z-value and most important the p-value (asymptotic significance). In this case the $\mathrm{p}=0.034$ shows the dominant type of corporate culture's strength in both local and multinational companies' sample (clan culture). Thus, since the agreed critical $\mathrm{p}$ - value of this study is .05(significance level), while the dominant type of culture is $\mathrm{p}=0.034$ is less than the agreed significance level of this study $p=.05$. This means that there is a significance difference between the strength of the dominant type of culture in both local and multinational companies, and that the result rejects the null hypothesis. Meanwhile the results also show that although the market culture is the second most dominant corporate culture in both types of companies, yet, there is also a marginal significant difference between both local and multinational $\mathrm{p}=0.053$. (See tables 3,4 and 5 that show the dominant type of culture's strength in both local and multinational companies and Mann-Whitney- Dominant type of culture's strength)

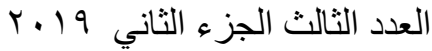

المجلد العاشر 
Organizational Culture in Local and Multinational Organizations in Egypt

Dr. Mohammad M. Al-Kalyoubi

\section{Discussion}

In view of the above, the analytical result of hypothesis (1) indicates that there is no significant difference between both local and multinational companies with regard to the most type of dominant culture; meaning that the results show that culture is the same in both local and multinational companies which is against the study's main assumption that states that corporate cultures are different between both local and multinational companies and that difference is one of the factors behind multinational companies higher financial performance versus local ones. On other words, results show that corporate culture is not one of the reasons behind any performance's distinction between both local and multinational companies operating in Egypt and that we should think of other reasons like leadership style, strategies and so on and so forth. Meanwhile, this result clearly shows the effect of Egyptian national culture on corporate culture. Moreover, this means that the result fails to reject the null hypothesis. Thus, Clan culture is the most dominant type of culture found in both local and multinational companies, 133 out of 206 respondents in the local companies' sample with the percentage of $54 \%$, while 35 respondents out of 87 which are the entire multinational companies' sample with the percentage $40 \%$ have chosen the Clan culture as the most dominant type of culture in their companies. It is logical to see that local companies' percentage is higher than the multinational one due to 
Organizational Culture in Local and Multinational Organizations in Egypt Dr. Mohammad M. Al-Kalyoubi

nature of local companies that could permit, in some cases, mistakes for the sake of people's adhesiveness, which is not the case in multinational companies that tend in most cases to put feelings aside when it conflicts with companies' interests. Meanwhile, this type of culture called a Clan because of its similarity to a family-type organisation in which the clan culture is dominant seems more like extended families than economical entities. Instead of the rules and procedures of hierarchies, the Clan culture is typified by a friendly place to work where people share a lot of themselves. Leaders are thought of as mentors and perhaps as parent figures. Organisation is held together by loyalty and tradition. Commitment is high. The organisation emphasizes the long-term benefit of individual development, with high cohesion and morale being important. Success is defined in terms of internal climate and concern for people. Organisation places a premium on teamwork, participation, and consensus. Meanwhile, the second most dominant type of culture is also the same in both local and multinational companies which is the market culture. Market culture is to a type of organisation that functions as a market itself. It is a result oriented organisation. The major concern is getting the job done. People are competitive and goal oriented. The leaders are hard drivers, producers, and competitors. They are tough and demanding. The glue that holds the organisation together is the emphasis on winning. Reputation and success are common concerns. The long 
Organizational Culture in Local and Multinational Organizations in Egypt Dr. Mohammad M. Al-Kalyoubi

term focus is on competitive actions and achievement of measurable goals and targets. Success is defined in terms of market share and penetration. The organisational style is harddriving competitiveness.

In this sense, it has not been expected that similarity with regard the dominant cultures' types found in both local and multination companies that might reflect, from one hand, the impact of national culture (Egyptian) on organisational culture and how strong is it, which has, to a certain extent, eliminated the effect of foreign companies' cultures on Egyptian workers. From the other hand, this result makes us think of other factors, rather than organisational culture that might have higher effect than culture on employees' performance that no doubt, is usually better in multinational rather than local Egyptian companies. Meanwhile, to test the strength of the clan culture as well as other corporate cultures, the researcher has counted the total points reported through adding A-B-C-D alternatives' responses for both total local companies and multinational samples.

In addition, it is not enough to accept similarity with regard to the most dominant type of culture in both local and multinational companies operating within the Egyptian setting without testing the strength of that type of culture in both, which leads us to the second hypothesis of this study. Therefore, although the analytical results show similarity between the dominant type of culture in both local and multinational 
Organizational Culture in Local and Multinational Organizations in Egypt Dr. Mohammad M. Al-Kalyoubi

companies operating within the Egyptian setting, yet, the strength of that dominant culture (clan culture) as well as the second most dominant type of culture ( Market culture) are different. The Clan culture represents $31 \%$ of local companies total accumulated responses against $28 \%$ in multinational companies, $\mathrm{p}$ value $=.034$, thus clan culture is more stronger in local companies than multinational ones which is logical as stated in the clan culture description mentioned above, yet, Market culture is stronger in multinational companies than local ones, as it represents $27 \%$ of the total multinational accumulated responses versus $25 \%$ in local companies value $=.053$ which is also a logical result. 
Organizational Culture in Local and Multinational Organizations in Egypt Dr. Mohammad M. Al-Kalyoubi

\section{References}

Barney, J.B. (1985) Organisational Culture: Can It Be A Source of Sustained Competitive Advantage?' Academy of Management Review, Vol.11 (3): pp 656-665.

Cameron, K. and Quinn R., (2006) Diagnosing and changing organisational culture- based on the competing values analysis, Jossey-Bass: San Francisco, pp. 3-4 and P. 117.

Cochran, W. G. (1963) Sampling Techniques, 2nd Ed., John Wiley and Sons Inc. :New York

Denison, D., (1984) Bringing corporate culture to the bottom Line, Organisational Dynamics, Vol. 13(2), pp. 5-22.

Denison, D., (June 2000) Organisational Culture: Can it be a Key Lever for Driving Organisational Change? International Institute for Management Development.

Deal T.E. and Kennedy A.A., (2000), corporate culture, the rites and rituals of corporate life, Perseus Books Publishing, P. IV.

Harrison, R., and Stokes, H., (1992) Diagnosing Organisational Culture, San Francisco: Jossey-Bass.

Haserot, P.W., (Sept., 2004) How to Create a High-Performance Culture, Of Counsel, Vol. 23, No. 9.

Kaliprasad, M., (June 2006) the Human Factor II: Creating a High Performance Culture in an Organisation, Cost Engineering Vol. 48, No. 6.

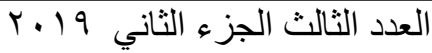

المجلد العانشر 
Organizational Culture in Local and Multinational Organizations in Egypt Dr. Mohammad M. Al-Kalyoubi

Kotter, J.P. and Heskett J.L., (1992) Corporate Culture and Performance, The free press, pp 68-80.

Miller, T. (September, 2004) 5 steps to creating a winning culture, Healthcare Financial Management.

Rollins, T., Roberts D., (1998) Work culture, Organisational Performance' and Business Success, Quorum Books.

Schermerhorn, J.R..,Hunt J.G., Richard N. Osborn, (2004) Core concepts of organisational behaviour, Jon Wiley and Sons, Inc.

Schwartz, H. and Davis, S.M., (1981) Matching Corporate Culture and Business Strategy, Organisational Dynamics, PP. 30-48.

Sørensen, J.B.,( December 2001) The Strength of Corporate Culture and the Reliability of Firm Performance, Massachusetts Institute of Technology.

Thompson, A.A. and Strickland, A.J., (1987) Strategic Management: Concepts and Cases, Forth Edition, Business Publications Inc. 
Organizational Culture in Local and Multinational Organizations in Egypt Dr. Mohammad M. Al-Kalyoubi

\section{TABLE 1}

Local and Multinational Companies' Dominant Type of Culture (Frequency Analysis)

\section{DOM_CU Dom. Culture *Q_8_1 Company Crosstabulation}

\begin{tabular}{|c|c|c|c|c|c|}
\hline & \multicolumn{2}{|c|}{ Q_8_1 Company } & \multirow[b]{2}{*}{ Total } \\
\hline & & & $\begin{array}{l}1 \text { Local } \\
\text { Company }\end{array}$ & $\begin{array}{l}2 \text { Multinational } \\
\text { Company }\end{array}$ & \\
\hline \multirow[t]{4}{*}{$\begin{array}{c}\text { DOM_CU } \\
\text { DOM.Culture }\end{array}$} & C_1 & $\begin{array}{c}\text { Count } \\
\% \text { of Total }\end{array}$ & $\begin{array}{c}113 \\
38.6 \%\end{array}$ & $\begin{array}{c}35 \\
11.9 \%\end{array}$ & $\begin{array}{c}148 \\
50.5 \%\end{array}$ \\
\hline & C_2 & $\begin{array}{c}\text { Count } \\
\% \text { of Total }\end{array}$ & $\begin{array}{c}19 \\
6.5 \%\end{array}$ & $\begin{array}{c}7 \\
2.4 \%\end{array}$ & $\begin{array}{c}26 \\
8.9 \%\end{array}$ \\
\hline & C_3 & $\begin{array}{c}\text { Count } \\
\% \text { of Total }\end{array}$ & $\begin{array}{l}52 \\
17\end{array}$ & $\begin{array}{c}31 \\
10.6^{\wedge}\end{array}$ & $\begin{array}{c}83 \\
28.3 \%\end{array}$ \\
\hline & C_4 & $\begin{array}{c}\text { Count } \\
\% \text { of Total }\end{array}$ & $\begin{array}{c}22 \\
7.5 \%\end{array}$ & $\begin{array}{c}41 \\
4.8 \%\end{array}$ & $\begin{array}{c}36 \\
12.3 \%\end{array}$ \\
\hline \multicolumn{3}{|c|}{$\begin{array}{l}\text { Total Count } \\
\% \text { of Total }\end{array}$} & $\begin{array}{c}206 \\
70.3 \%\end{array}$ & $\begin{array}{c}87 \\
29.7 \%\end{array}$ & $\begin{array}{c}293 \\
100.0 \%\end{array}$ \\
\hline
\end{tabular}


Organizational Culture in Local and Multinational Organizations in Egypt Dr. Mohammad M. Al-Kalyoubi

\section{TABLE 2}

Mann-Whitney- Local and Multinational Companies' Type of Dominant Corporate Culture

Ranks

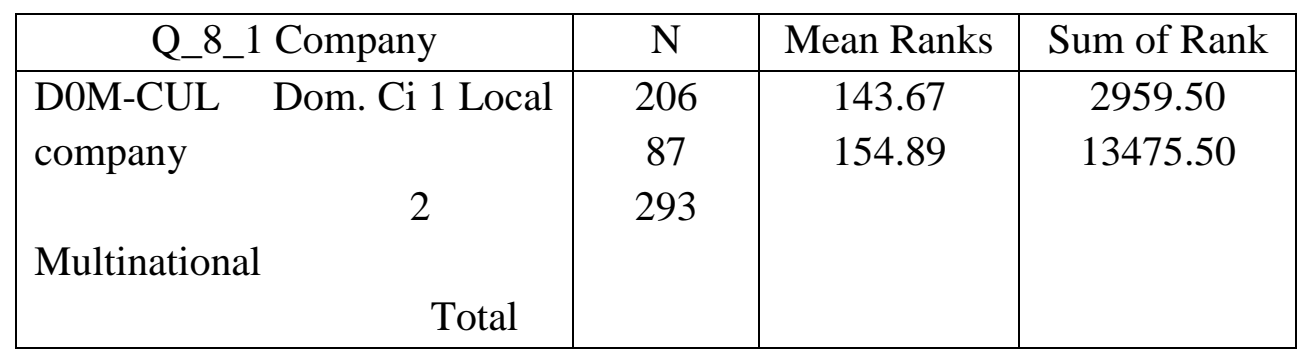

Test Statistics a

\begin{tabular}{|c|c|}
\hline & DOM-CUL \\
& Dom. Culture \\
\hline Mann- Whiteney U & 8274.500 \\
Wilcoxon & 29595.500 \\
$\mathrm{Z}$ & -1.037 \\
Asymp. Sig ( 2-tailed) & .300 \\
\hline
\end{tabular}

a. Grouping Vriable: Q_8_1 Company 
Organizational Culture in Local and Multinational Organizations in Egypt Dr. Mohammad M. Al-Kalyoubi

\section{TABLE 3}

Dominant Type of Culture's Strength (Local Companies)

\begin{tabular}{|c||c|c|}
\hline $\begin{array}{c}\text { Organizational Culture } \\
\text { Type }\end{array}$ & Accumulated Score & Percentage \\
\hline \hline Clan culture & 39085 & $31 \%$ \\
\hline \hline Adhocracy Culture & 27338 & $22 \%$ \\
\hline Market Culture & 31207 & $25 \%$ \\
\hline \hline Hierarchy Culture & 27554 & $22 \%$ \\
\hline
\end{tabular}

\section{TABLE 4}

Dominant Type of Culture's Strength (Multinational Companies)

\begin{tabular}{|c||c|c|}
\hline $\begin{array}{c}\text { Organisational Culture } \\
\text { Type }\end{array}$ & $\begin{array}{c}\text { Frequencies( total } \\
\text { responses) }\end{array}$ & Percentage \\
\hline \hline Clan culture & 14456 & $28 \%$ \\
\hline \hline Adhocracy Culture & 10612 & $21 \%$ \\
\hline \hline Market Culture & 14146 & $27 \%$ \\
\hline \hline Hierarchy Culture & 12114 & $24 \%$ \\
\hline
\end{tabular}


Organizational Culture in Local and Multinational Organizations in Egypt Dr. Mohammad M. Al-Kalyoubi

TABLE 5

Mann-Whitney-Dominant Type of Culture's Strength

\begin{tabular}{|c||c||c|c|c|}
\hline $\begin{array}{c}\text { Type of } \\
\text { Culture }\end{array}$ & $\begin{array}{c}\text { Mann- } \\
\text { Whitney U }\end{array}$ & Wilcoxon W & Z & $\begin{array}{c}\text { Asymp.Sig. (2- } \\
\text { tailed) }\end{array}$ \\
\hline \hline Clan culture & 7560.000 & 11388.000 & -2.115 & .034 \\
\hline \hline $\begin{array}{c}\text { Adhocracy } \\
\text { Culture }\end{array}$ & 8225.000 & 12053.000 & -1.112 & .266 \\
\hline $\begin{array}{c}\text { Market } \\
\text { Culture }\end{array}$ & 7677.500 & 28998.500 & -1.938 & .053 \\
\hline $\begin{array}{c}\text { Hierarchy } \\
\text { Culture }\end{array}$ & 8350.000 & 29671.000 & -.923 & .356 \\
\hline
\end{tabular}

